ANL-6186

Chemistry - General

(TID-4500, 15th Ed.)

AEC Research and

Development Report

ARGONNE NATIONAL LABORATORY

9700 S. Cass Avenue

Argonne, Illinois

COUNTING INDIVIDUAL ALPHA

ACTIVITIES IN MIXTURES

by

John Sadauskis

Radiological Physics Division

June 1960

Operated by The University of Chicago

under

Contract W-31-109-eng-38 


\section{DISCLAIMER}

This report was prepared as an account of work sponsored by an agency of the United States Government. Neither the United States Government nor any agency Thereof, nor any of their employees, makes any warranty, express or implied, or assumes any legal liability or responsibility for the accuracy, completeness, or usefulness of any information, apparatus, product, or process disclosed, or represents that its use would not infringe privately owned rights. Reference herein to any specific commercial product, process, or service by trade name, trademark, manufacturer, or otherwise does not necessarily constitute or imply its endorsement, recommendation, or favoring by the United States Government or any agency thereof. The views and opinions of authors expressed herein do not necessarily state or reflect those of the United States Government or any agency thereof. 


\section{DISCLAIMER}

Portions of this document may be illegible in electronic image products. Images are produced from the best available original document. 
TABLE OF CONTENTS

$\underline{\text { Page }}$

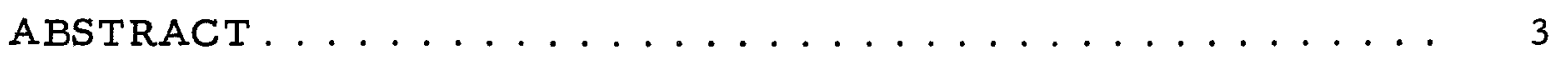

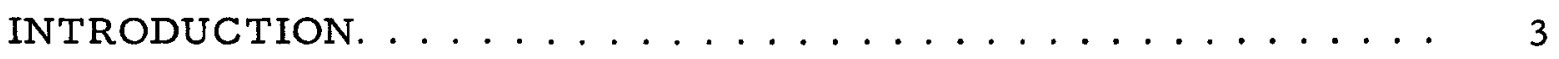

PREPARATION OF SOURCES. . . . . . . . . . . . . . . 3

SINGLE THIN ALPHA SOURCES ................. 5

THIN MULTIPLE ALPHA-PARTICLE SOURCES . . . . . . . . . 7

THIN MULTIPLE ALPHA-PARTICLE SOURCES WITH

COMPONENTS OF LARGE VARIATION IN ACTIVITY. . . . . . . . 9

$\mathrm{Am}^{241}-\mathrm{Pu}^{239} \mathrm{MIXTURES} \ldots \ldots \ldots \ldots \ldots$

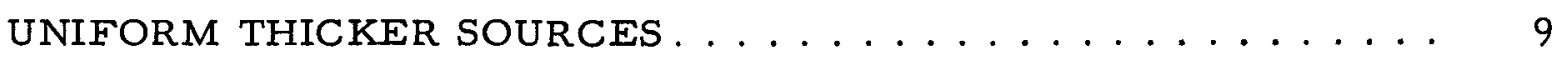

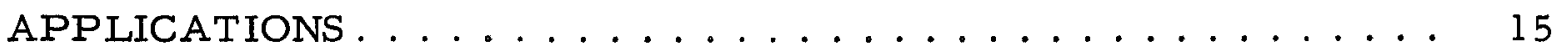

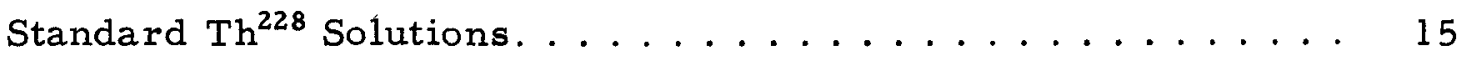

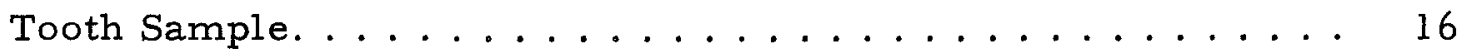

$\mathrm{U}^{235}$ in Natural Uranium. ......................... 17

Percent of $\mathrm{Ra}^{226}$ Decay to the Excited State........... 18

VARIATION IN SOURCE PREPARATION . . . . . . . . . . 19

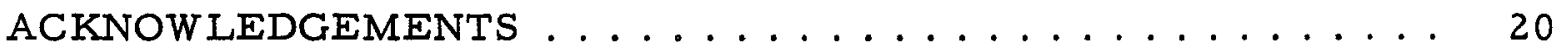




\title{
COUNTING INDIVIDUAL ALPHA ACTIVITIES IN MIXTURES
}

\author{
by
}

John Sadauskis

\begin{abstract}
A reproducible method for directly determining individual alpha activities in mixtures in which there are sufficient differences in alpha energies to give separation of the spectrum peaks was developed. A gridded ionization chamber, connected with a 10-channel analyzer, at first, and later to a 100-channel analyzer, was used together with suitably thin source.(1) The chamber gas was a mixture of $90 \%$ argon and $10 \%$ methane.
\end{abstract}

\section{INTRODUCTION}

The alpha-particle spectra of thin sources consist of a main peak, a tail which extends from the main peak to zero energy, and smaller peaks caused by decay to excited states. The smaller peaks usually merge with the main peak; if they do not and are of sufficient magnitude, they can be handled as separate alpha energies.

The problem of counting individual alpha activities can be considered as being twofold: (1) a method to produce thin sources must be developed in order to concentrate as many counts as possible in the main peak, and to make the main peak as narrow as possible; and (2) in the case of the overlapping of spectra, a procedure to determine with sufficient accuracy the total number of counts belonging to each spectrum must be developed.

\section{PREPARATION OF SOURCES}

The common method of source preparation involves the deposition of a solution containing radioactive material on a solid backing and evaporating the solvent until the residue is deposited. The area covered by the solution at the time that saturation is reached during the evaporation process determines largely the area that the residue will cover, since deposition usually occurs first at the edges of the solution. It can be readily seen that if the solution is spread over a larger area at the time of saturation, a thinner deposit will usually be obtained. 
To some extent the spreading of the solution is governed by the following equation:

$$
\cos \theta=\frac{\gamma_{S}-\gamma_{L S}}{\gamma_{L}}
$$

where $\theta$ is the angle of contact that the edge of the solution makes with the solid backing, $\gamma_{S}$ is the surface tension or free surface energy of the solid backing surface, $\gamma_{L S}$ is the interfacial tension between the solution and solid backing, and $\gamma_{I}$ is the surface tension of the solution. As the value of the fraction increases, the contact angle becomes smaller and the solution will cover a larger area. At a value of the fraction equal to one, the entire surface will be wetted. Thus it is seen that the lower is the surface tension of the solution, $\gamma_{L}$, the larger will be the spreading.

Thin sources have been prepared by various investigators from solutions of radioactive materials dissolved in organic solvents which, of course, usually have lower surface tensions than those of aqueous solutions. In general, the surface tension of the solid surfaces of materials used for source mounts would be sufficiently large to cause considerable spreading of the solution were it not that such surfaces are contaminated rather quickly after preparation; this results in a reduction of the free surface energy and thereby hinders spreading. Thus the cleanliness of surface mounts is an important factor in the preparation of thin sources.

Various materials were tried as mounts for the determination of $\mathrm{Am}^{241}$ activity (see Table 1). In some cases new surfaces were used to take advantage of the high free surface energy. The highest contrast between uncleaned and clean surfaces was found in the case of platinum. Two sources of $\mathrm{Am}^{241}$ activity were prepared on new platinum discs by identical preparation methods, except that one disc was heated with an induction heater to a red heat and allowed to cool prior to depositing the solution. For a 10-channel region which included the spectrum peak and covered a $170-\mathrm{kev}$ region, the unflamed disc source gave $54 \%$ of the total $2 \pi$ count, while the flamed disc source gave $83 \%$; a 20 -channel region for the flamed disc gave $92 \%$. Figure 1 shows the total 50-channel plot. It can be readily seen that if the first 20-channel count of the spectrum could be obtained directly, a $10 \%$ error in the estimation of the remainder would result in only about $1 \%$ error in the total count.

In this report the channels of a spectrum or spectra are numbered in order of decreasing energy, the one of highest energy being channel 1 , the second highest channel 2, and so forth. The channel numbers on the abscissa of the figures, being different, are from the instrument used and are arranged in a manner which was most convenient at the time.

New, flamed platinum discs were found to be the best backing materials tried. These could be used with ordinary procedures to provide a suitable standard method of preparation of thin sources. 
Table 1

THE EFFECTS OF VARIOUS MOUNTING MATERIALS

IN DETERMINING $\mathrm{Am}^{241}$ ACTIVITIES

Percent of $2 \pi$ count obtained Percent of $2 \pi$ count with 10-channel analyzer, for for 50-channel ana170-kev region including spec- lyzer, for $850-\mathrm{kev}$

Backing Material trum peak region with peak

Stainless steel disc, cleaned with conc. nitric acid and carbon tetrachloride

Stainless steel disc, sanded to remove old surface

New platinum disc; no cleaning

New platinum disc: cleaned by heating with induction heater

Aluminized mylar; no cleaning

Freshly split mica

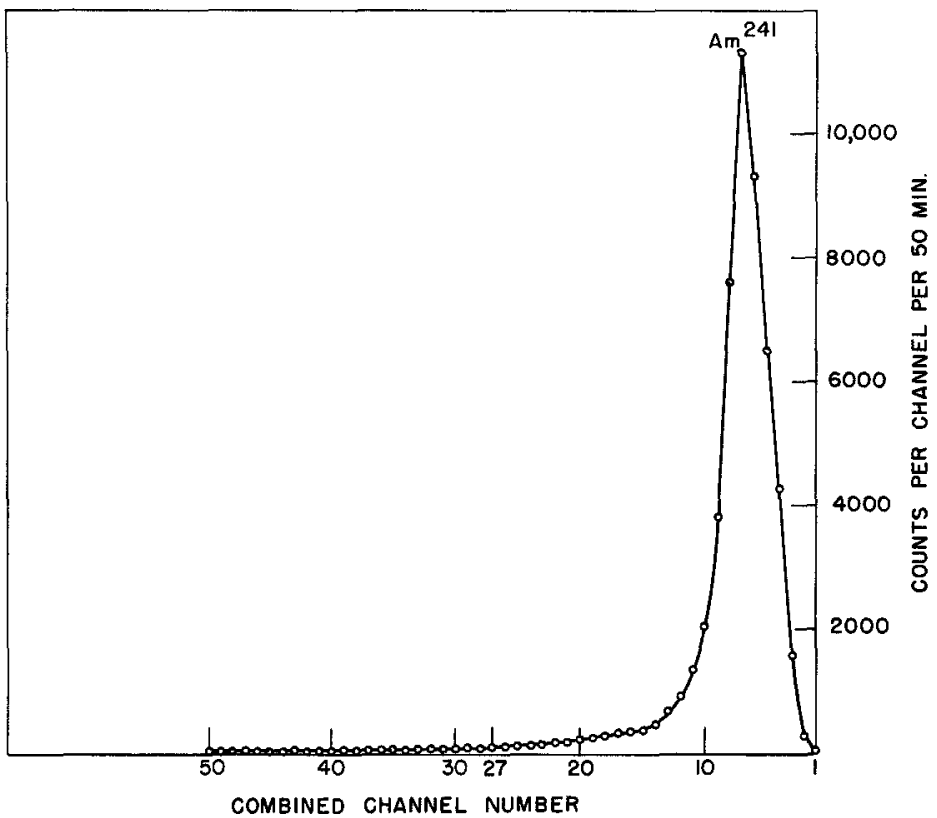

Fig. 1 Spectrum of $\mathrm{Am}^{241}$ activity. Runs at five settings of the 10 channel band in adjacent parts of the spectrum were required to get the 50 channel combination. Channel width is $17 \mathrm{kev}$.

\section{SINGLE THIN ALPHA SOURCES}

The procedure of actually making a count while keeping the gain settings constant on the pulse analyzer consisted of determining the complete spectrum to sufficient accuracy, adding up a chosen number of channels 
which included the peak, and multiplying this total by a previously determined factor to get the total $2 \pi$ count. A total of 50 channels was chiefly used, and the spread of $17 \mathrm{kev}$ per channel was used throughout for thin sources. The general method for estimating the contribution from the tail or low-energy part of the spectrum, where overlapping occurred, into another spectrum was based on the assumption that for thin sources all spectra are sufficiently similar to permit application of the same factors or ratios within the accuracy required here.

A comparison of the distributions of counts in various portions of the spectrum was made for individual sources of $\mathrm{Am}^{241}$ (5.48 Mev), $\mathrm{Pu}^{239}$ (5.15 Mev), and $\operatorname{Th}^{230}(4.68 \mathrm{Mev})$. The results are summarized in Table 2 in which some of the data have been normalized to the counting rate obtained in a standard $2 \pi$ alpha counter. A consistent value of 0.95 was obtained for the fraction of total counting rate in the 50 channels $(850 \mathrm{kev}$ ) extending downward from the high-energy portion of the peak. The fraction (0.92) obtained for 26 channels was also consistent enough to permit use where counting time was limited with the 10-channel analyzer used.

Table 2

\section{DISTRIBUTION OF COUNTS IN SPECTRA OBTAINED} FROM SOURCES OF $\mathrm{Am}^{241}, \mathrm{Pu}^{239}$, and $\mathrm{Th}^{230}$

\begin{tabular}{|c|c|c|c|c|c|}
\hline Nuclide & $F_{50}$ & $F_{26}$ & $K_{27}$ & $K_{50}$ & $\begin{array}{c}\text { Final Slope after } \\
50 \text { Channels } \\
\text { (\% Decrease per } \\
10 \text { Channels) }\end{array}$ \\
\hline +vecine & +50 & +26 & $\underline{\Lambda_{27}}$ & $11_{50}$ & \\
\hline $\mathrm{Am}^{241}$ & 0.949 & 0.934 & 728 & 2184 & 13.6 \\
\hline $\mathrm{Pu}^{239}$ & 0.949 & 0.910 & 295 & 899 & 46.0 \\
\hline$T h^{230}$ & 0.944 & 0.911 & 359 & 960 & 19.7 \\
\hline Average & 0.947 & 0.918 & 461 & 1348 & 26.4 \\
\hline
\end{tabular}

$F_{50}=\mathrm{cpm}$ in 50 channels $/ \mathrm{cpm}$ in $2 \pi$ counter

$F_{26}=\mathrm{cpm}$ in 26 channels $/ \mathrm{cpm}$ in $2 \pi$ counter

$\mathrm{K}_{50}=$ Ratio of the sum of counts in channels to the right of channel containing 0.1 of the number of counts in the peak channel (cf. Fig. 1) to the number of counts in channel 50.

$\mathrm{K}_{27}$ is defined for channel 27 as $\mathrm{K}_{50}$ was defined for channel 50 .

The values of " $K$ " and the final slopes in Table 2 are measures of the fraction of total activity to be found in the tails of the spectra. As 
expected from the smaller difference between $F_{50}$ and $F_{26}$ for $A^{241}$ than for the other two nuclides, a considerably smaller fraction of the counts is found in channel 27 or channel 50 for $\mathrm{Am}^{241}$ than for $\mathrm{Pu}^{239}$ or $\mathrm{Th}^{230}$. On the other hand, the number of counts per channel beyond channel 50 decreased more slowly for $\mathrm{Am}^{241}$, as is to be expected from the constant values of $F_{50}$. Thus, if one extrapolates a spectrum beyond 26 channels on the basis of average values of $K_{27}, K_{50}$, and slope ( $T$ able 2 ), errors in the region from channels 27 to 50 tend to be cancelled by errors in the region beyond channel 50. Figure 2 shows an extrapolated slope for the $\mathrm{Am}^{241}$ spectrum given in the first figure.

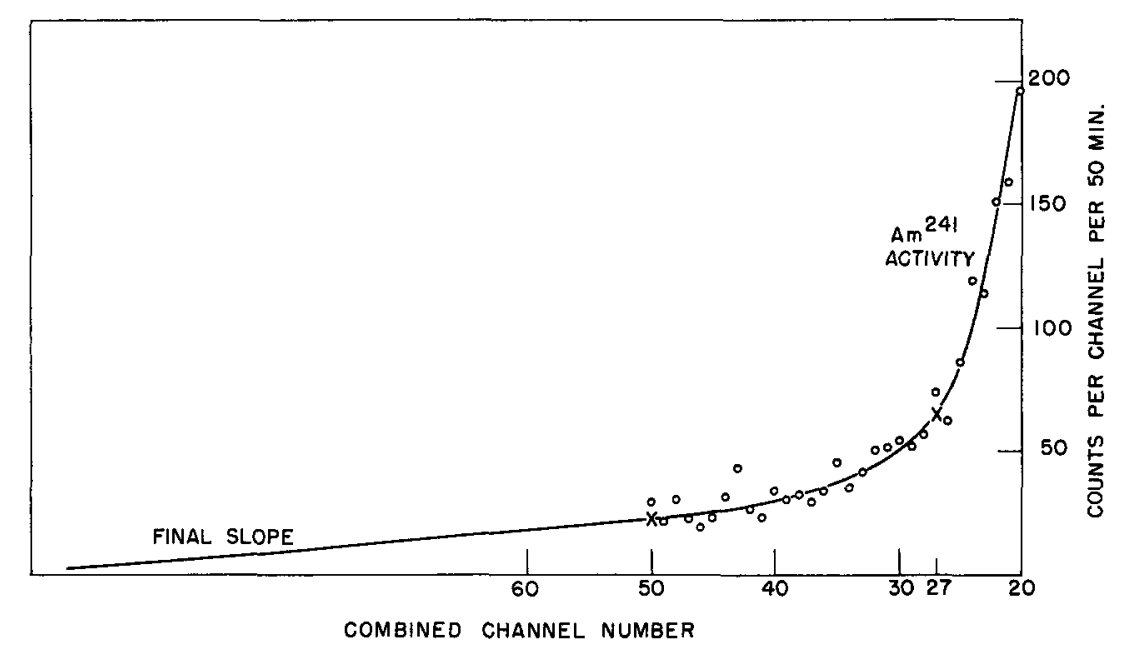

Fig. 2

Am $\mathrm{m}^{241}$ data of Fig. 1 plotted on an expanded vertical scale. Crosses at channels 27 and 50 designate the positions of estimated channel counts that were used as guides for work with multiple spectra. Channel width is $17 \mathrm{kev}$.

\section{THIN MULTIPLE ALPHA-PARTICLE SOURCES}

The procedure adopted for analysis of multiple spectra was as follows:

(1) The total counting rate of the nuclide with the highest energy alpha particle was determined by applying standard factors (e.g., $F_{26}$ ) to the observed counts in the region of the peak.

(2) The spectral tail of the nuclide was extrapolated, using values of $\mathrm{K}_{27}, \mathrm{~K}_{50}$, and the slope.

(3) The contribution of the first spectrum to the next peak was subtracted to provide the net value of the activity of the nuclide with the next most energetic alpha particles. 
(4) The total counting rate and extrapolated tail of the second group were determined, and the process continued until the spectra were fully resolved.

The accuracy of determining components in a mixture of alpha activities is affected by the spread in alpha-particle energies, the relative intensities of the components, and the thickness of the source. Where one or more components have a low count rate relative to the others, a modification in the method must be used; this is dealt with later. Furthermore, thicker sources also require modification and they too are covered later.

As a means of determining how well the average factors obtained in Table 2 might be applied to multiple sources, sources consisting of mixtures of $\mathrm{Th}^{230}$ (4.68 Mev), $\mathrm{Pu}^{239}$ (5.15 Mev), and $\mathrm{Am}^{241}$ (5.48 Mev) of known activity were prepared in which the ratios of the activities of the components was varied 20 or 30 percent. These were analyzed for individual activities, and a typical plot is shown in Fig. 3. The agreement between the determined count and the known count was within 3 percent.

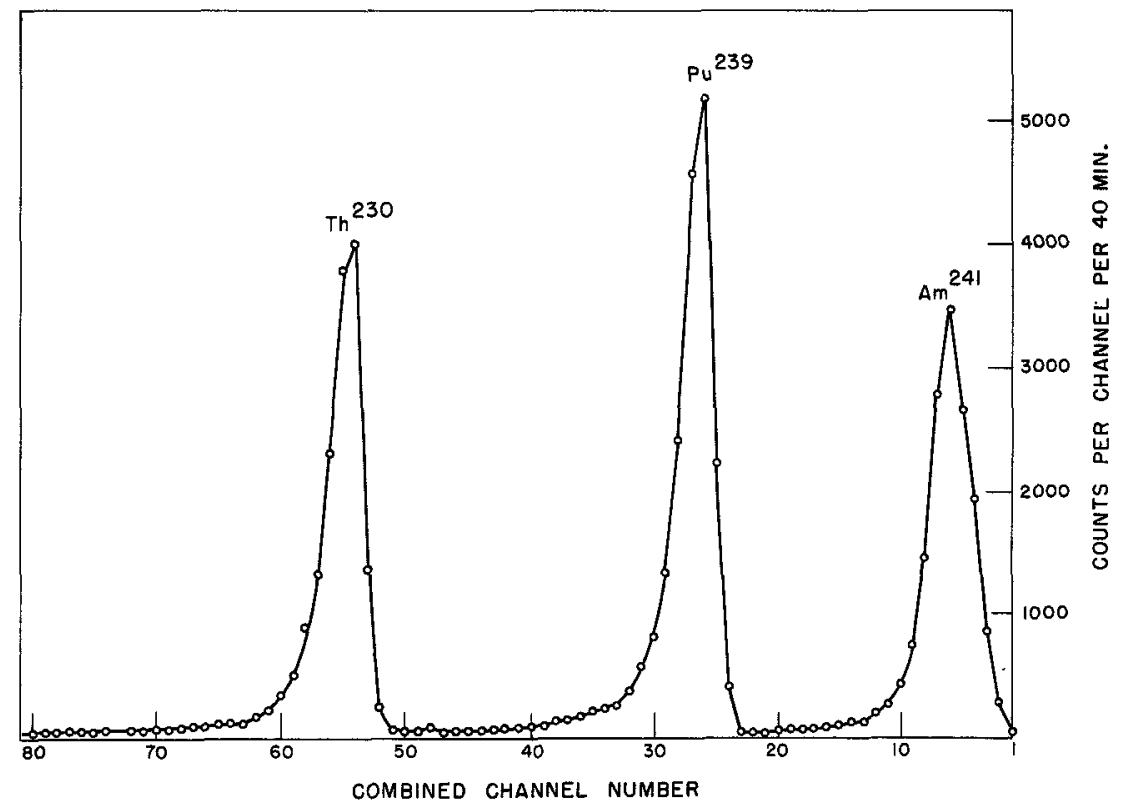

Fig. 3

Typical spectra obtained from thin source containing $\mathrm{Th}^{230}, \mathrm{Pu}^{239}$, and $\mathrm{Am}^{241}$ activities which was used to check reliability of method for determining individual activities. Channel width is $17 \mathrm{kev}$.

Certain cases require individual variation of the above general method. The spectrum of $\mathrm{Ra}^{226}$, for example, is obtained complete for 50 channels, but superimposed on a small background from daughters of higher energies. Estimating the counting rate for $\mathrm{Ra}^{226}$ in channel 50 by 
means of $K_{50}$ and subtracting it from the observed value at that channel gives the count from other activities at this point. By drawing a line from this point to that where the $\mathrm{Ra}^{226}$ should provide zero count to the right of channel 1 enables one to estimate the contribution from other sources to the counting rate in the 50-channel region. The activity of a $\mathrm{Ra}^{226}$ solution which had been calibrated by radon measurement was checked, and the determined count was within $2 \%$ of the radon measurement.

\section{THIN MULTIPLE ALPHA-PARTICLE SOURCES WITH COMPONENTS OF LARGE VARIATION IN ACTIVITY}

By a modification of the above method, counting of components of low activity, present with those of high activity and higher energy, can be made. Complete spectra of the lower activities are determined first, starting with that of highest energy and going downward in energy. After subtraction of the spectra of low activities from the combined spectra, the nuclides of higher activities can be counted by the method already given.

The isolation of a low-activity spectrum for counting in cases where there was considerable energy separation of the nuclides, 300 kevorgreater, was accomplished by drawing a trial curve to channel 27 , as is shown in Fig. 4, this curve (the broken line) representing the zero level of the lower activity. For the spectrum thus isolated, the channel 27 count was calculated as described previously and compared with the value on the plot. The curve was redrawn (not shown) and the channel 27 count recalculated until agreement was reached between the calculated and observed channel 27 values. The spectrum could readily be extrapolated to completion if necessary. With a knowledge of the 26 channels of the spectrum it is possible to calculate the $2 \pi$ count as before.

\section{$\mathrm{Am}^{241}-\mathrm{Pu}^{239}$ MIXTURES}

A thin source containing $\mathrm{Am}^{241}$ and $\mathrm{Pu}^{239}$ activities of known count and of approximate count ratio 10 to 1 , respectively $y_{2}$ was used to check the method. The 100-channel analyzer set at $17 \mathrm{kev}$ per channel was used here. Fifteen determinations of the $\mathrm{Pu}^{239}$ activity, of approximately 10,000 counts each, were made. The difference between the determined and known counts was less than $4 \%$ in all cases, except one where it was $6 \%$. Figure 4 shows a plot used for an isolation of the $\mathrm{Pu}^{239}$ spectrum. Determinations of the $\mathrm{Am}^{241}$ activity agreed within $3 \%$ of the known value.

\section{UNIFORM THICKER SOURCES}

It is difficult to put a boundary between thin and thicker sources. Here, thin sources were those, in general, whose contribution to the full width at half height of the peak was $25 \mathrm{kev}$ or less. Thicker sources whose 


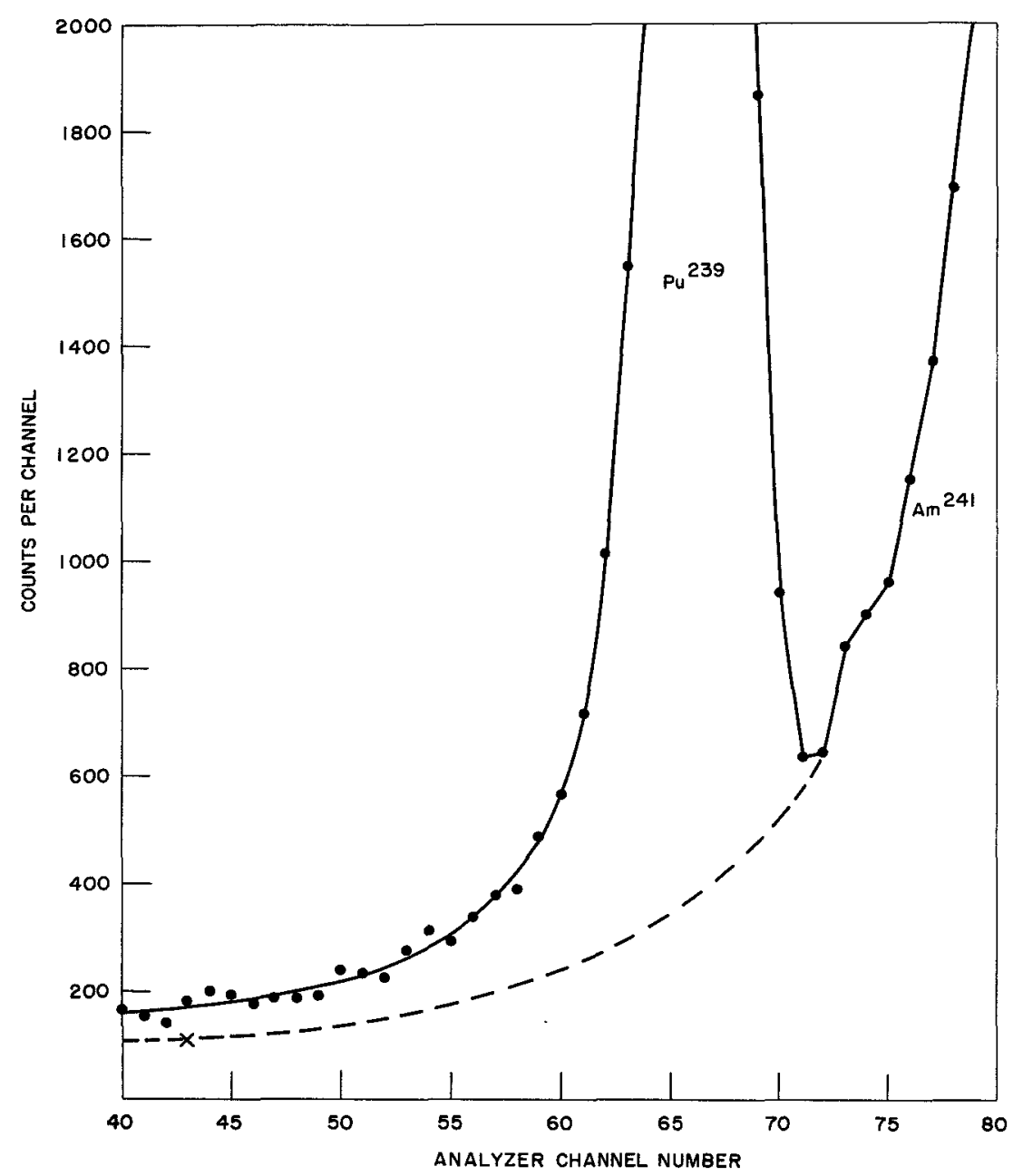

Fig. 4

Plot used to isolate $\mathrm{Pu}^{239}$ spectrum from combined $\mathrm{Pu}^{239}, \mathrm{Am}^{241}$ spectra. Count of channel 27 of the $\mathrm{Pu}^{239}$ spectrum, indicated by a cross, was used in determining the final isolating curve. Channel width is 17 kev.

contribution to the peak width was as high as $120 \mathrm{kev}$ were considered usable for estimation of individual activities. Source contribution to width at onehalf peak height was checked by comparison with a peak obtained with a pulse generator.

The general variation in pulse distribution with thickness of source is shown in Fig. 5. The differences in thicknesses of the three $\mathrm{Am}^{241}$ sources on platinum were caused by variation in preparation. The distribution with the lowest peak is from a source on a new platinum disc with no cleaning. The distribution with intermediate peak height is the same source after flaming, and the one with the highest peak is from a new platinum disc cleaned by flaming before deposition of the $\mathrm{Am}^{241}$ solution and flaming again after preparation. The $2 \pi$ count rate of all three sources was normalized to the same value. 


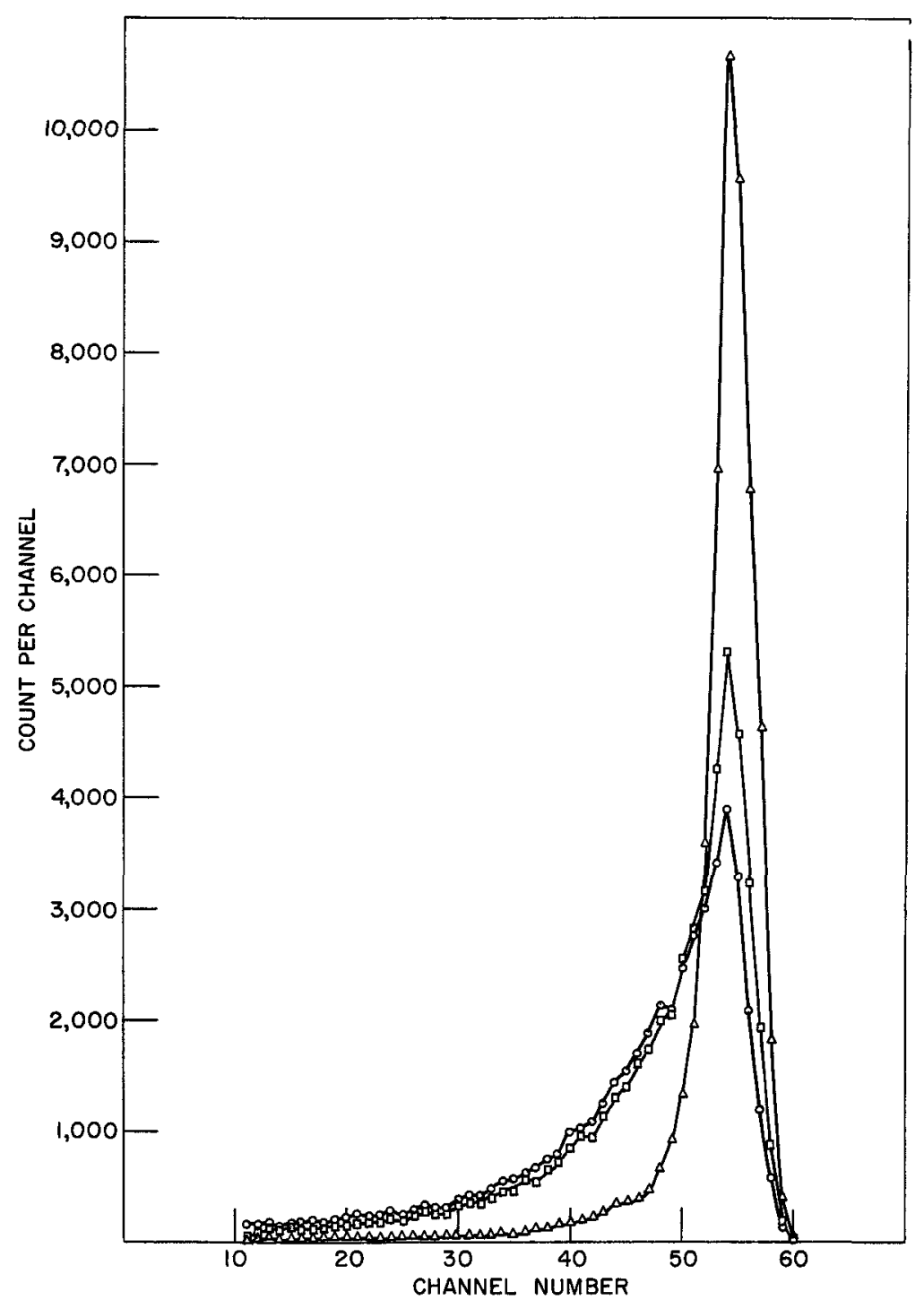

Fig. 5

Three spectra from $\mathrm{Am}^{241}$ activity on new platinum backings normalized to the same count rate. Chan nel width is 17 kev. O Platinum disc not cleaned $b$ efore deposition of $\mathrm{Am}^{241}$ solution, not flamed afterward. $\square$ Above source after flaming. $\triangle$ Platinum disc, flamed before deposition of solution, flamed after preparation.

Some totals from the data used for Fig. 5 are shown in Table 3. As can be seen, the three totals under $T_{1}$ and $T_{2}$ do not show very large variation. This behavior can be used in the process of estimating counts of thicker, uniform sources.

For thicker sources it was more advantageous to work with $35 \mathrm{kev}$ per channel. The quantities $\mathrm{K}_{21}$ and $\mathrm{K}_{30}$ were determined with individual thin sources of $\mathrm{Am}^{241}, \mathrm{Pu}^{239}$, and $\mathrm{Th}^{230}$ by the same procedures as $\mathrm{K}_{26}$ and $\mathrm{K}_{50}$ were determined previously (Table 2), except here the fraction of the peak channel count used was 0.05 instead of 0.1 , since the energy per channel was approximately doubled. Spectra of individual thicker sources of the same nuclides were also used and the number of channels of the thicker sources equivalent to 21 and 30 channels for thin sources were determined in the same manner as channel equivalents for 11 and 20 channels were 
Table 3

\section{SMALL VARIATION IN TOTALS OF EQUIVALENT NUMBERS OF CHANNEL COUNTS FROM Am ${ }^{241}$ SPECTRA}

Characteristic feature of $\mathrm{Am}^{241}$ source preparation $\underline{\text { using new platinum discs }} \quad \underline{\mathrm{T}_{1}} \quad \underline{\mathrm{N}_{1}} \quad \underline{\mathrm{T}_{2}} \quad \underline{\mathrm{N}_{2}}$

Platinum disc cleaned by flaming, source flamed after preparation $48,000 \quad 11$ channels $52,000 \quad 20$ channels

Platinum disc not cleaned, flamed after preparation $45,000 \quad 25$ channels $49,000 \quad 38$ channels Platinum disc not cleaned, source not flamed after preparation 44,00030 channels $48,000 \quad 45$ channels

$\mathrm{T}_{1}=$ total of channel counts to right of channel containing 0.1 of the number of counts in the peak channel.

$N_{1}=$ number of channel (counts) included to get $T_{1}$.

$\mathrm{T}_{2}=$ total for 20 channels or total of channel counts equivalent to 20 channels. The equivalent number $\left(\mathrm{N}_{2}\right)$ was obtained by dividing the channel 20 count of the top distribution into its $T_{1}$ value to get $K_{20}$. $K_{20}$ was divided into the other $T_{1}$ values to get the corresponding channel count whose location on the corresponding spectrum was used to get the corresponding value of $\mathrm{N}_{2}$ (number of channels to right of identified channel).

$\mathrm{N}_{2}=$ number of channel counts included to get $T_{2}$.

determined in Table 3. From the data obtained, Fig. 6 was plotted; this shows the number of channels equivalent to 21 and 30 channels versus full width at one-half peak height of the spectra of the sources of varying thickness. For all individual thicker sources used, an average factor, call it $F_{21}$, was determined, which represented the ratio of the total of the 21 channel equivalent counts to the $2 \pi$ count, and was similar to $F_{26}$ and $F_{50}$ of Table 2 .

As a visual aid in extrapolating individual spectra of mixtures, single spectra of thicker sources were combined graphically; one such combination is shown in Fig. 7 , which is a combination of $\mathrm{Am}^{241}, \mathrm{Pu}^{239}$, and $\mathrm{Th}^{230}$ spectra. 


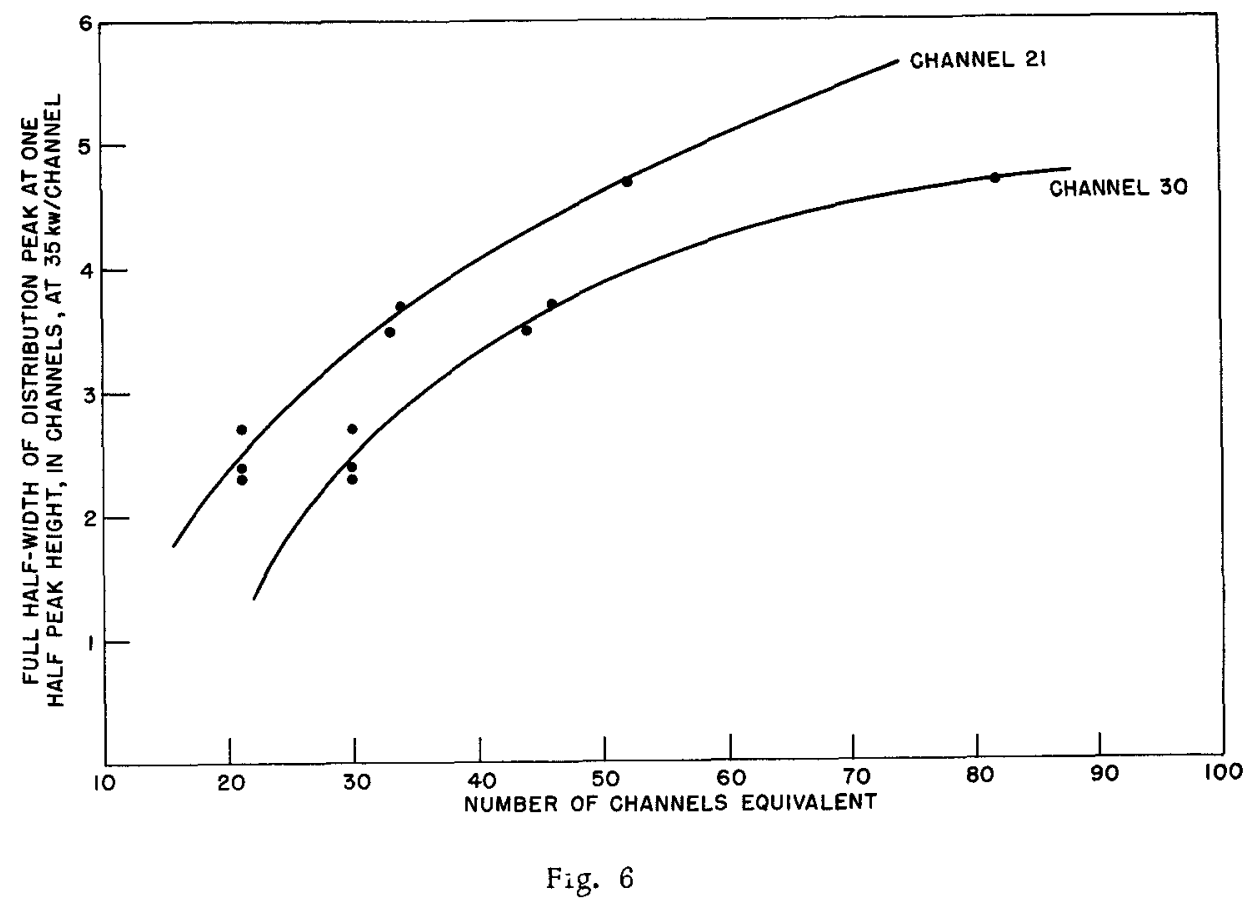

Number of channels for thicker sources that are equivalent to 21 and 30 channels of thin sources. The total of the channel counts of equivalent channel numbers are approximately equal. Plots used for work with multiple spectra from thicker sources.

The procedure for the analysis of multiple spectra of thicker sources was almost the same as for thin sources, the chief exception being, of course, that the positions of the 2 channel counts that were determined for guides in extrapolation of the tail varied with source thickness. These positions were determined from Fig. 6 for a first trial. If the extrapolation in question were too different from a graphic combination (Fig. 7), by comparison, then the extrapolation was drawn from past experience, as an estimation.

The slope after channel 30 or channel equivalent to channel 30 was found to be close to zero.

The spectrum finally arrived at was treated in the customary manner; 0.05 of the peak channel count gave the count which isolated the channels for the first total; this total divided by the appropriate factor $\left(\mathrm{K}_{21}\right)$ gave the count which isolated the channels equivalent to 21 channels; the total of these channel counts was divided by the appropriate geometry factor $\left(F_{21}\right)$ to get the $2 \pi$ count.

Figure 8 shows a situation where the locations of the positions of the channel counts to be used as guides in extrapolating the tail for $\mathrm{Pu}^{239}$, determined from the plot of Fig. 6, were considered to be inaccurate, so, in addition, an extrapolation was made as an estimation from past 


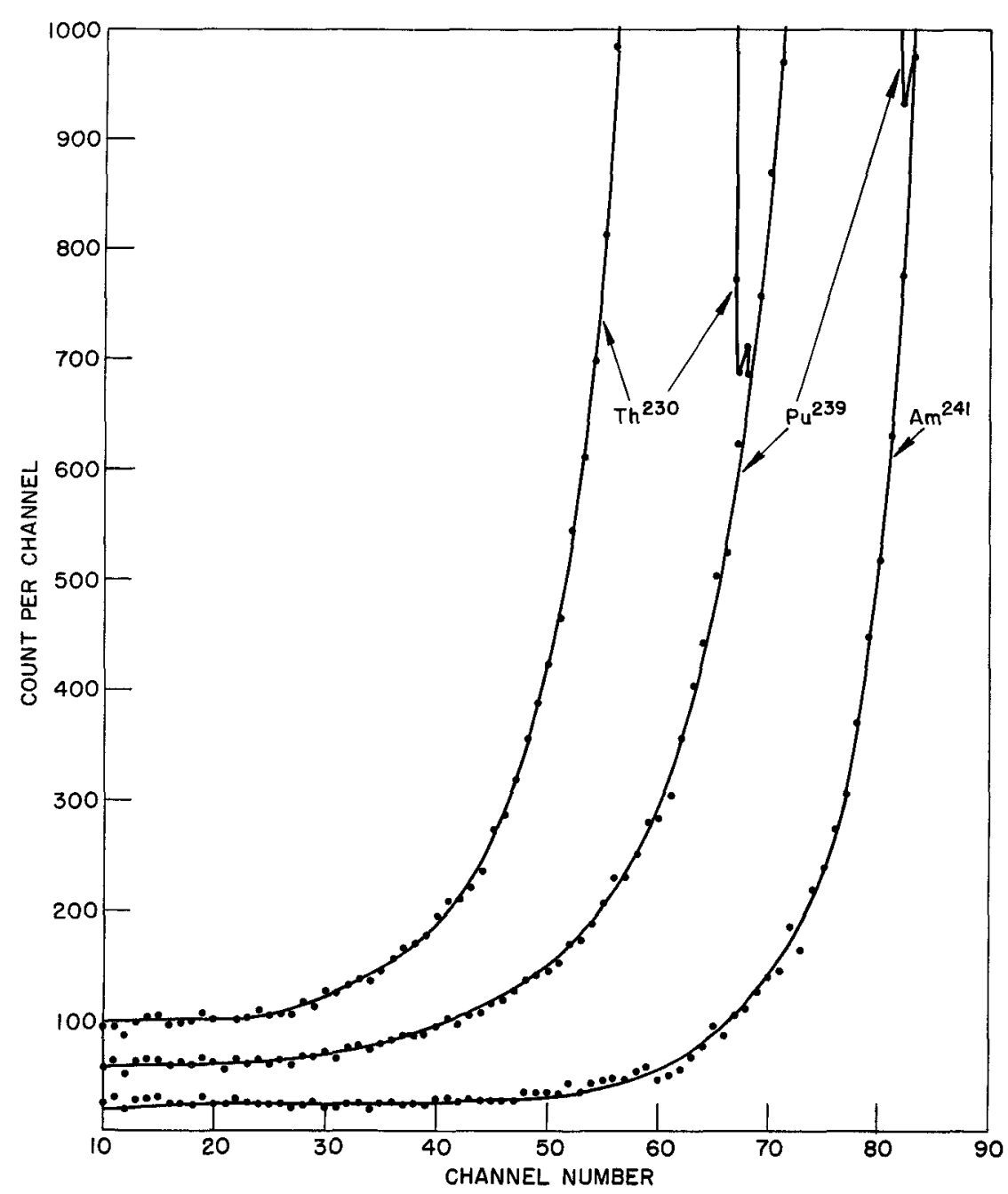

Fig. 7

Single spectra of thicker sources of $\mathrm{Th}^{230}, \mathrm{Pu}^{239}$, and $\mathrm{Am}^{241}$ combined graphically, used as a visual aid for extrapolation of single spectra of multiple sources. Channel width is 35 kev.

experience. The final $2 \pi$ count for $\mathrm{Pu}^{239}$, using the values from Fig. 6 in the extrapolation, gave an error of $10 \%$, while the case of the extrapolation made visually gave an error of $5 \%$.

Two thicker source mixtures of known count were used for a check of the method. After some experience with thicker sources, the error of the determined count compared with the known count of the individual activity was $6 \%$ or less for these two sources. 


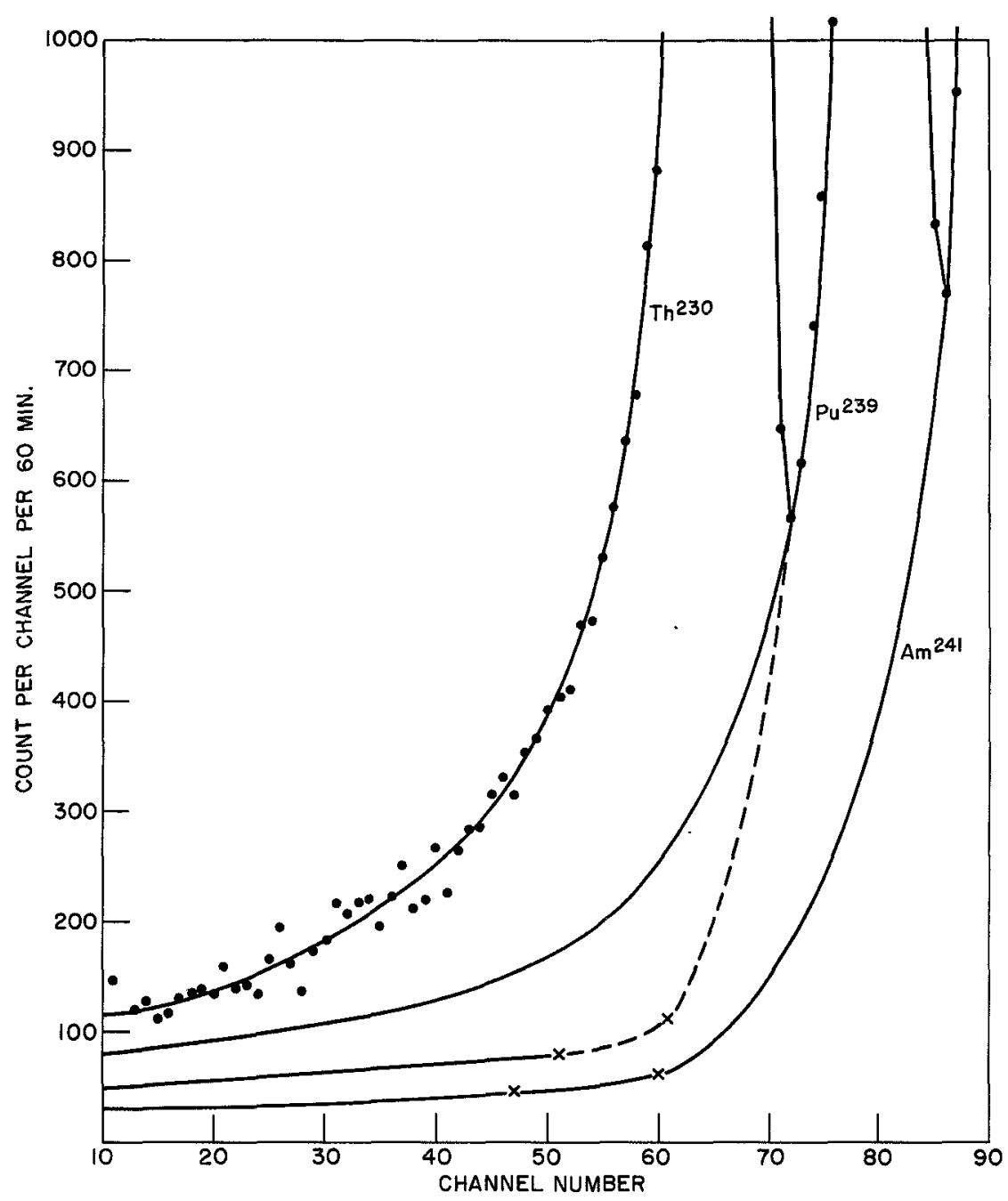

Fig. 8

Spectra obtained from thicker source containing $\mathrm{Th}^{230}, \mathrm{Pu}^{239}$, and $\mathrm{Am}^{241}$ activities. Crosses on extrapolations of $\mathrm{Am}^{241}$ and $\mathrm{Pu}^{239}$ indicate 21 and 30 equivalent channel positions obtained from Fig. 6 . In the case of $\mathrm{Pu}^{239}$ (dotted line) the extrapolation was too different from Fig. 7 and therefore not used; the solid line drawn as an approximation was used instead. Channel width is $35 \mathrm{kev}$.

\section{APPLICATIONS}

\section{Standard $\mathrm{Th}^{228}$ Solutions}

The ratio of activities of $\mathrm{Th}^{228}$ to $\mathrm{Th}^{232}$ was checked for two solutions used as standards for $\mathrm{Th}^{228}$. One which was prepared from thorium purified sometime between 1906 and 1917 and having a calculated ratio of 
$0.99 \begin{aligned} & +0.005 \\ & -0.01\end{aligned}$ was analyzed, and the ratio found to be $0.99 \pm 0.05$. The purification of the thorium of the second solution dated back to 1946. Its calculated ratio was $0.63 \pm 0.015$. Two runs were taken on it and both gave $0.67 \pm 0.03$. The possible errors associated with results, here and elsewhere in the report, are 0.9 errors.

The same thorium solutions were found to contain $\mathrm{Th}^{230}$ as an impurity. The ratio of activities of $\mathrm{Th}^{230}$ to $\mathrm{Th}^{232}$ in the older solution was found to be $0.21 \pm 0.01$, while for the newer solution it was $0.12 \pm 0.01$.

Tooth Sample

The ratio of $\mathrm{Th}^{232}$ to $\mathrm{Th}^{228}$ was also determined for thorium isolated from a tooth obtained from a patient who had taken thorium salts internally. The thorium was extracted into a mixture of carbon tetrachloride and dibutyl phosphate, and the organic phase ashed on a platinum disc. The activities found were: $2.24 \pm 0.10 \mathrm{dpm}$ of $\mathrm{Th}^{228}, 0.58 \pm 0.05 \mathrm{dpm}$ of $\mathrm{Th}^{232}$, and a very small amount of $\mathrm{Th}^{230}$. A plot of the activities is shown in Fig. 9. Similar results were obtained on the same sample by comparison of $\mathrm{Th}^{228}$ measured by the dibutyl phosphate procedure $(2)$ combined with the total alpha counting rate of the thorium in the ashed DBP as measured with a $2 \pi$ counter: values of $2.6 \pm 0.2 \mathrm{dpm}$ and $0.8 \pm 0.4 \mathrm{dpm}$ were obtained for $\mathrm{Th}^{228}$ and $\mathrm{Th}^{232}$, respectively.

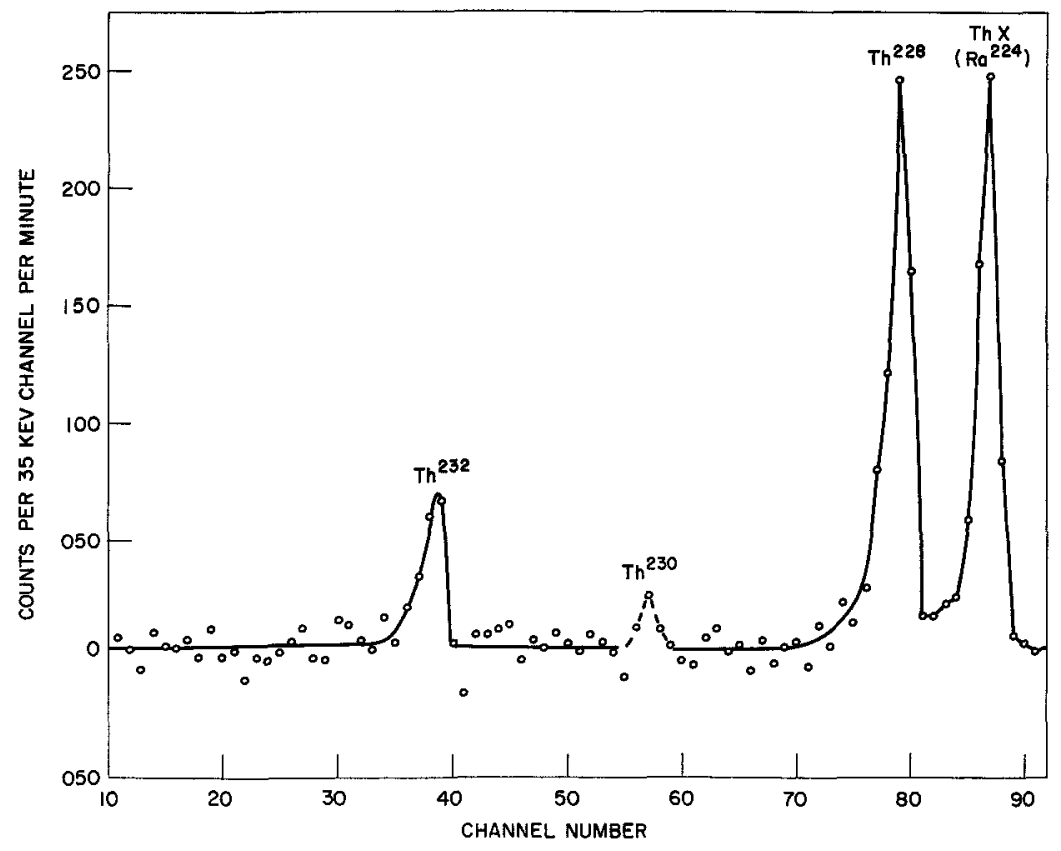

Fig. 9

Thorium isotopes present in tooth sample. For each channel, instrument background was subtracted from the total channel count. Some channels have a negative count because of statistical fluctuation, (see curve). 


\section{$\mathrm{U}^{235}$ In Natural Uranium}

A determination of $\mathrm{U}^{235}$ in natural uranium was made as a rigorous check of the method as applied to those cases in which the magnitudes of the individual activities are different. In order to obtain a sufficiently high count rate for $\mathrm{U}^{235}$ from a platinum mount, $\frac{15}{16}$ inches in diameter, some thickness in the uranium source had to be tolerated. Figure 10 shows the spectra of $\mathrm{U}^{238}, \mathrm{U}^{235}$, and $\mathrm{U}^{234}$ as recorded by the 100-channel analyzer at a count rate of approximately 5 counts per minute of $U^{235}$. A check showed the $\mathrm{U}^{234}$ count to be equal to the $\mathrm{U}^{238}$ count within $2 \%$. From the data for $\mathrm{U}^{234}$, a factor for calculating the channel 12 count was determined, as well as the ratios of the highest count channel to the counts of the other channels of the peak. In isolating the $\mathrm{U}^{235}$ spectrum, the procedure was almost the same as before for the case of the mixture of $\mathrm{Pu}^{239}$ and $\mathrm{Am}^{241}$, shown in Fig. 4. One exception was that the highest count channel was first estimated for $\mathrm{U}^{235}$ and, using the ratios from the $\mathrm{U}^{234}$ data, the other channels of the peak were calculated. These were used as guides for drawing the trial curve isolating the $\mathrm{U}^{235}$ spectrum. For the isolated spectrum, channel 12 was calculated and compared with the observed count in the isolated

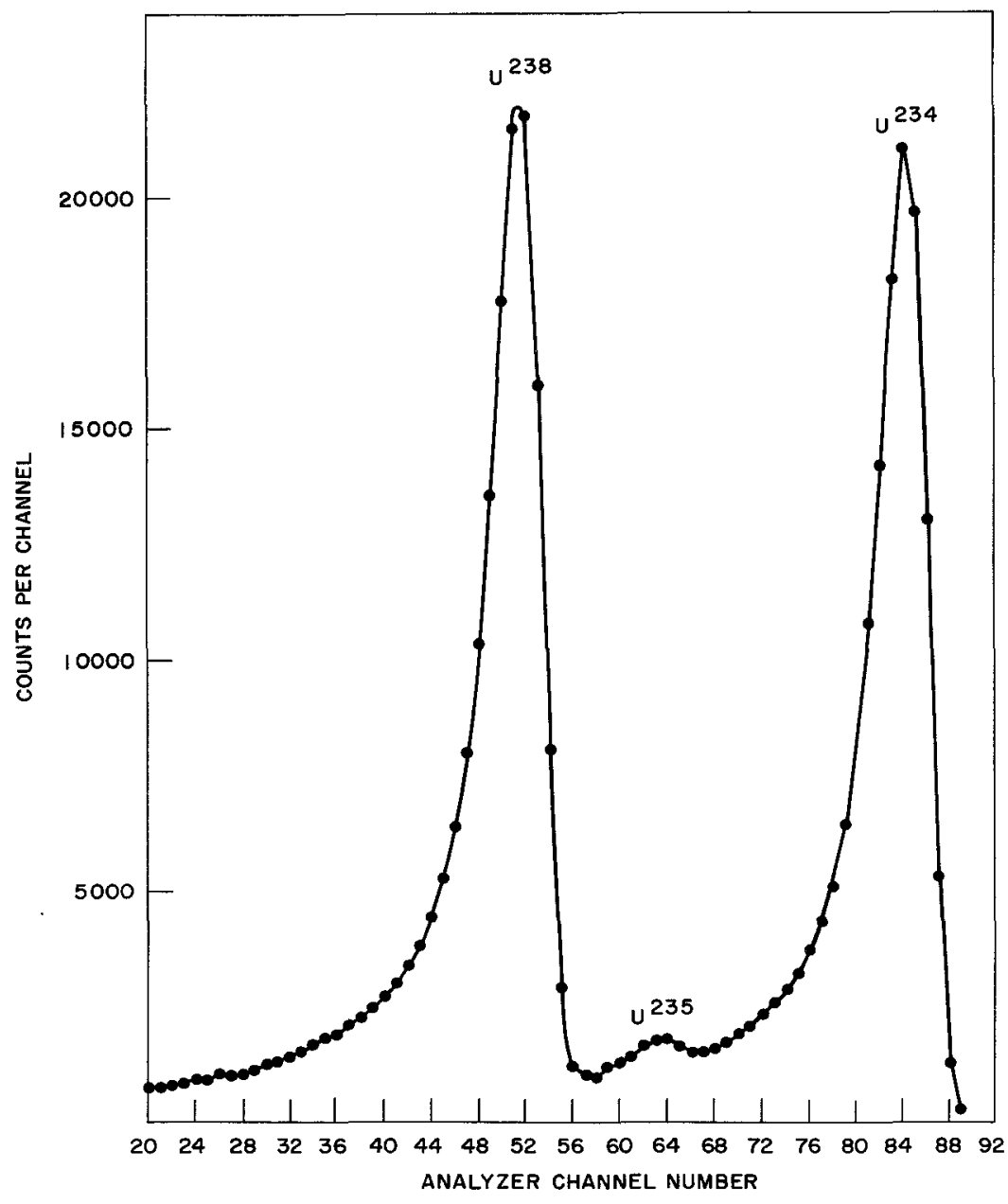

Fig. 10 Spectra of $\mathrm{U}^{238}, \mathrm{U}^{235}$, and $\mathrm{U}^{234}$ activities in natural uranium. Channel width is $17 \mathrm{kev}$. 
spectrum. The process was repeated until the calculated and observed counts were in agreement. Figure 11 shows the isolated $\mathrm{U}^{235}$ spectrum. The ratio of the sums of the counts for $U^{235}$ and $U^{238}$ in the first 12 channels was used to calculate the percentage of $\mathrm{U}^{235}$ present. Two runs were taken of approximately 4,000 and 6,000 counts of $U^{235}$, and values of $0.65 \%$ and $0.69 \%$ were obtained, respectively, for the percentage of $U^{235}$ present as compared with an accepted value of $0.71 \%$.

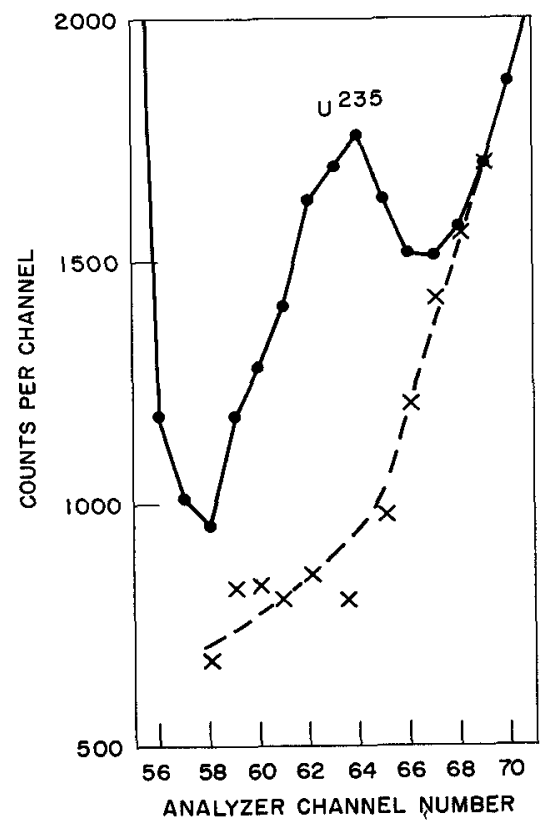

Fig. 11

Isolated spectrum of $\mathrm{U}^{235}$. Crosses are zero level points that were calculated and used as guides in drawing the isolating curve. Channel width is 27 kev.

\section{Percent of $\mathrm{Ra}^{226}$ Decay to the Excited State}

The percent of $\mathrm{Ra}^{226}$ atoms that decay to the excited state was determined. The source used was $\mathrm{Ra}^{226}$ adsorbed to fused quartz, and two mil Lektromesh was used for collimation to avoid trouble from conversion electrons. (3) The resolution of the excited state peak is seen in Fig. 12. The excited state count and total count were obtained. Results of four runs are given in Table 4, and the average of the four runs, each weighted according to the total number of counts taken, is $5.7 \%$ which is the same value as that obtained by Asaro and Perlman. (4)

Table 4

RUNS WITH Ra ${ }^{226}$ FOR DETERMINATION OF EXTENT OF DECAY TO THE EXCITED STATE

$\begin{array}{ccccc}\text { Run } & \text { Time for Run } & \begin{array}{c}\text { Excited } \\ \text { State Count }\end{array} & \text { Total Count } & \begin{array}{c}\text { Percent Decay } \\ \text { to Excited State }\end{array} \\ 1 & 1,486 \mathrm{~min} . & 590 & 10,200 & 5.8 \\ 2 & 1,487 \mathrm{~min} . & 590 & 10,400 & 5.7 \\ 3 & 1,486 \mathrm{~min} . & 620 & 10,500 & 5.9 \\ 4 & 6,832 \mathrm{~min} . & 2,700 & 47,400 & 5.7 \\ & & & \text { weighted average } & \frac{5.7}{5.7}\end{array}$




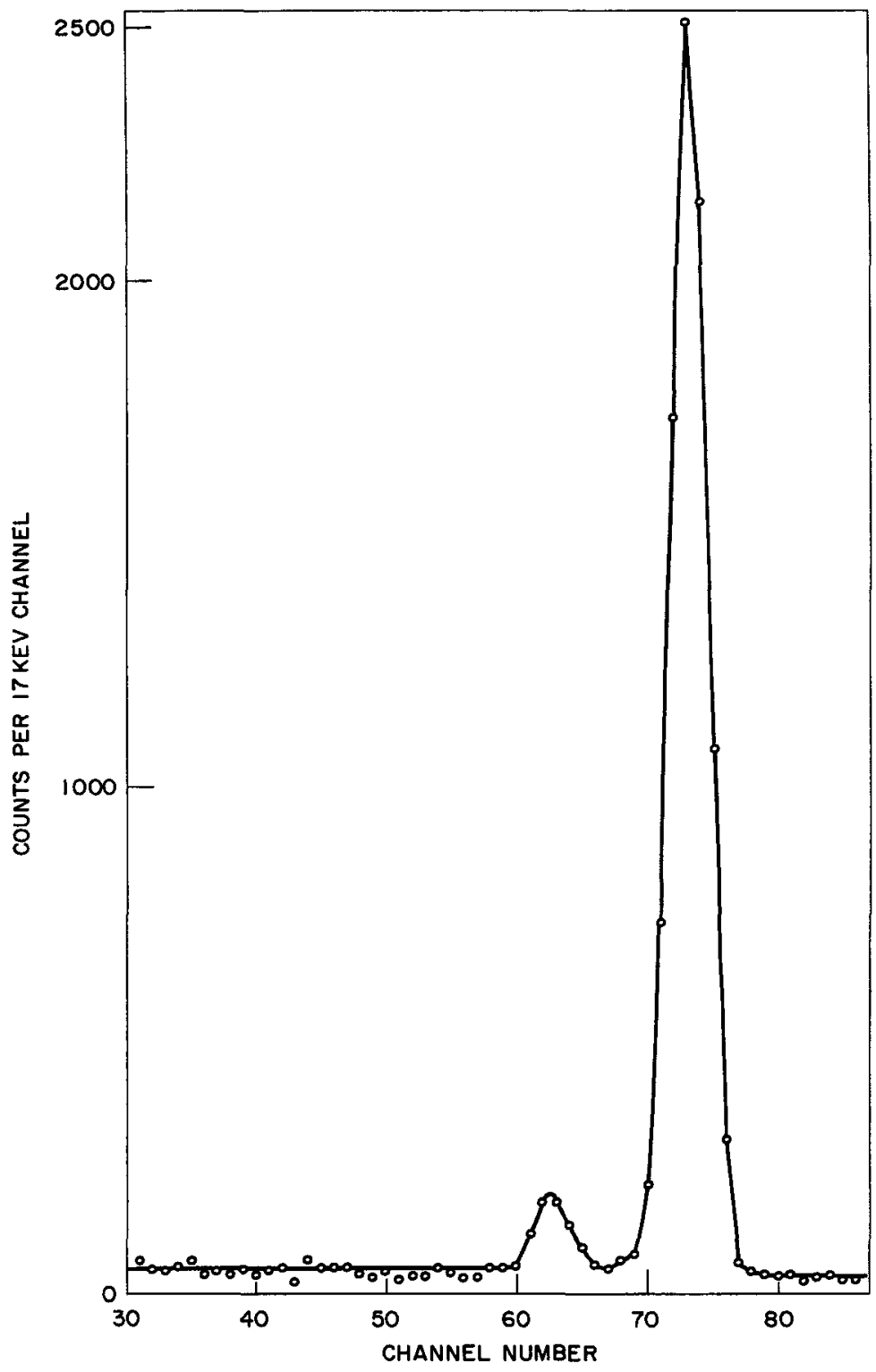

Fig. 12

Alpha particle spectrum of $\mathrm{Ra}^{226}$. Source used was $\mathrm{Ra}^{226}$ adsorbed to fused quartz with 2 mil Lektromesh for collimation.

\section{VARIATIONS IN SOURCE PREPARATION}

In order to have the final evaporation from an organic solvent in some cases, a few drops of ethylene glycol were added to the active solution on the platinum disc. The initial evaporation removed most of the water and the final deposition was from an ethylene glycol solution with possibly a small amount of water. It was checked beforehand, of course, that there would be no chemical reaction of the radioactive solution with the ethylene glycol.

For some solutions containing considerable residue, an inert gas was blown on the deposited solution to keep it spread out during evaporation. Furthermore, solutions containing barium salts appeared to contaminate clean platinum surfaces rather quickly which prevented spreading of the solution. This procedure was useful for this type of situation. 
These variations of source preparation are useful for measurement of ratios of activities, but carry some risk in preparing sources for absolute measurement since some of the activity can be lost by their use. The individual technique using these variations should be checked for loss of activity if application is considered to absolute work.

\section{ACKNOW LEDGMENTS}

The author wishes to express thanks to Dr. Andrew F. Stehney for various helpful suggestions, to Dr. Dorothy $E$. Wallace for her work in the preparation of the tooth sample and to Harold A. May for construction of the chamber and pulse analyzer and for their maintenance during use.

\section{REFERENCES}

1. The chamber of modified Los Alamos design was used in conjunction with a pulse analyzer developed by Harold A. May, Radiological Physics Division. The electronic circuit was similar to that described by D. W. Engelkemeir and L. B. Magnusson, Rev. Sci. Instr., $\underline{26}, 295$ (1955).

2. A. F. Stehney, D. E. Wallace and F. H. Ilcewicz, Radiological Physics Division. Semiannual Report, ANL-5596, pp. 12-14 (Jan. - June 1956).

3. D. W. Engelkemeir and L. B. Magnusson, Rev. Sci. Instr., Vol. 26, pp. 295-302 (1955).

4. F. Asaro and I. Perlman, Phys. Rev., Vol. 88, p. 129 (1952), also Table of Isotopes Rev. Mod. Phy. Vol. 30-Z-Part II p. 806 (1958). 